\title{
Advice given to women in Argentina about breast-feeding and the use of alcohol
}

\author{
M. Yanina Pepino ${ }^{1}$ and Julie A. Mennella ${ }^{1}$
}

Suggested citation

Pepino MY, Mennella JA. Advice given to women in Argentina about breast-feeding and the use of alcohol. Rev Panam Salud Publica. 2004;16(6):408-14.

ABSTRACT Objective. To explore the types of advice that women in Argentina received from health professionals, family members, and friends about drinking alcoholic beverages and about alcohol usage during pregnancy and lactation.

Methods. In December 2001 and December 2002, structured interviews were conducted with a total of 167 women who were then breast-feeding or who had recently breast-fed their infant. Mothers were asked about the type of advice, if any, that they had received about the use of alcohol from health professionals and from family members and friends. Also included were questions related to the usage of the traditional Argentine beverage "mate" (an infusion widely consumed in South America that is prepared from the leaves of the Ilex paraguayensis plant) and the types of advice the women had received about breast-feeding and neonatal care in general.

Results. Of the 167 women studied, 96.4\% of them reported that their physician had advised them to breast-feed their infant. In addition, $93.4 \%$ of the women said they had treated their infant's umbilical cord stump with alcohol. Fewer than half of the women (46.7\%) reported that their physician had advised them about drinking alcoholic beverages during pregnancy, and even fewer (25.7\%) received such advice during lactation. Family and friends were about equally likely to give advice about the consumption of alcoholic beverages during pregnancy $(42.6 \%)$ and during lactation (47.9\%). However, the type of advice changed, with the family and friends being significantly more likely to encourage drinking when the women were lactating than when they were pregnant $(\mathrm{P}<0.001)$. Family members and friends also encouraged the drinking of mate to increase milk production.

Conclusions. As in other cultures, in Argentina the belief exists that alcohol enhances lactation. However, the majority of women whom we interviewed had not been counseled by their health professional about the consumption of alcoholic beverages during pregnancy and lactation. There is a need for professional development strategies that will address women's awareness of the risks of alcohol consumption and alcohol usage.

Keywords Alcohol drinking; ethanol; breast feeding; maternal behavior; health knowledge, attitudes, practice; Argentina.

1 Monell Chemical Senses Center, Philadelphia, Pennsylvania, United States of America. Send correspondence to: M. Yanina Pepino, Monell Chemical Senses Center, 3500 Market Street, Philadelphia, Pennsylvania 19104-3308, United States of America; telephone: 215-573-5026; fax: 215-8982084; e-mail: ypepino@monell.org
The alcohol consumed by pregnant women can readily cross the placenta, and that exposure puts children at risk for fetal alcohol syndrome, a cluster of physical abnormalities (e.g., facial malformations, growth retardation) and neurodevelopmental abnormalities (e.g., mental retardation) (1). In the United States of America, fetal alcohol syndrome is the leading preventable 
cause of mental retardation, affecting an estimated one child per 1000 live births (2). Fetal alcohol syndrome is an international problem that affects children whenever women consume alcohol during pregnancy (3).

Because there is reasonable evidence of harm, and because safe levels of alcohol consumption are not established, medical authorities in North America and some European countries (e.g., Austria, Denmark, Ireland, Sweden) recommend that pregnant women or those planning a pregnancy avoid alcohol consumption entirely $(4,5)$. The possible impact that a woman's drinking alcoholic beverages during pregnancy has on her and her child, as well as on society as a whole, makes it vital to use routine prenatal clinical visits to communicate this information to women.

If the mother chooses to drink alcohol after birth, the baby can be additionally exposed to alcohol that is in the mother's breast milk. The amount of ethanol transmitted to human milk is a minute fraction of that consumed by the mother (less than $2 \%$ of maternal dose) (6-9). Therefore, occasional exposure is often considered insignificant, and many authorities, such as the Committee on Drugs of the American Academy of Pediatrics in the United States, regard ethanol as a "drug usually permissible with breast-feeding" (10). However, recent research strongly suggests that exposure to ethanol via mothers' milk affects breast-fed infants in several important ways.

First, drinking alcohol during lactation may actually be counterproductive in the short term. Exposure to alcohol in the mother's milk alters an infant's sleep-wake cycles $(11,12)$, and a human infant consumes approximately $20 \%$ less breast milk during the hours immediately following the mother's consumption of an acute dose of alcohol $(8,9,13)$. That decrease in milk intake is due in part to depression in milk production by the mother $(14,15)$.

Second, gross motor development at one year of age is slightly, but significantly, altered in infants who are exposed regularly (at least daily) to alco- hol in the mother's milk (16). The association between maternal drinking and the child's motor development persisted even after more than one hundred potentially confounding variables were controlled for during pregnancy and the first three months after delivery.

Third, the extensive animal-model research of Juan Carlos Molina and colleagues at the Instituto de Investigaciones Médicas Mercedes y Martín Ferreyra (the Mercedes and Martín Ferreyra Institute of Medical Research), which is located in the city of Córdoba, Córdoba, Argentina, has shown that alcohol consumption by rats during pregnancy and lactation leads to the infant rats having alcohol-related sensory memories that increase their alcohol consumption later in life (17-19). Some of these findings have recently been extended to human infants born at the Hospital Universitario de Maternidad y Neonatología (University Maternity and Neonatology Hospital), which is also in the city of Córdoba. Newborns of women who drank moderately during pregnancy exhibited heightened reactivity to alcohol odor in comparison to newborns of women who drank less (20). Because maternal ethanol consumption distinctly flavors mothers' milk $(8,9)$, and such changes are detected by the infant $(8,9,14)$, a large body of research has shown that sensory learning also occurs when the infant experiences alcohol in its mother's milk $(14,21)$.

From a public health standpoint we need to determine why alcohol consumption during pregnancy and breast-feeding are important risk factors for the developing child. We also need to explore the beliefs surrounding why women who are not alcoholics drink alcoholic beverages during pregnancy, the peripartum period, and lactation.

Obviously, a primary force shaping the way alcohol is used and the consequences of its usage is culture (22). Beliefs about the medicinal properties of alcohol attain particular importance during pregnancy and lactation. The lore of many cultures suggests that alcohol consumption and usage can ben- efit both mothers and infants. Medical practice dating back to the 1800 s indicates that soaking the umbilical cord with alcohol prevents umbilical infections and accelerates cord detachment (23). Although this practice is limited to cleaning the cord stump in some countries (23-25), the practice of treating the cord stump with gauze soaked with 180-proof ethyl alcohol persists in some Latin America countries (18). It is important to emphasize here that this practice can lead to significantly high blood alcohol concentrations in the infant $(26,27)$.

Another long-standing belief is that drinking alcohol has galactogenic (milk-producing) results for lactating women (28). These women are often advised that consuming alcohol will improve the quality and quantity of their milk, facilitate milk letdown, and help their babies get a good night's sleep (29). The type of beverage believed to possess galactogenic properties varies among cultures. For example, women in Mexico are encouraged to daily drink as much as two liters of pulque (a low-alcohol beverage made of the fermented juice of a local fruit, Agave atrovirens) during both pregnancy and lactation (30). Indochinese women in California drink wine steeped with herbs (31), whereas the magic elixir in Spain (32) and Germany (33) is malt beer. The belief that alcoholic beverages are galactagogues is ingrained in current-day medical practice in United States. That is evident from a recent study (29), which found that the majority of lactating women reported that health professionals advised them to abstain from drinking during pregnancy. However, one-quarter of the women reported that they were encouraged to consume alcohol once they began lactating.

In Argentina there is a paucity of research on beliefs and practices related to alcohol usage during pregnancy, the peripartum period, and lactation. Therefore, the goal of the research described in this article was to determine what beliefs and practices exist in Argentina.

In December 2001 and December 2002 we surveyed women living in the 
two largest cities of Argentina, Buenos Aires and Córdoba, about the types of advice they had received from health professionals, family members, and friends, and their beliefs and practices related to alcohol usage during pregnancy, the peripartum period, and lactation. We also wanted to determine whether the advice women received about alcohol consumption during pregnancy differed from the advice that they received during lactation, and whether the type of advice women received from health professionals differed from that received from family members and friends. Our study also included questions related to beliefs regarding breast-feeding in general and the usage of "mate," an infusion prepared from the leaves of the Ilex Paraguayensis plant. That beverage is widely consumed throughout South America and is an integral part of cultural life and folk beliefs there $(34,35)$.

\section{METHODS}

\section{Subjects}

The study subjects were 177 women who were surveyed at local medical clinics, in city plazas, and outside shopping malls in Buenos Aires and Córdoba. Only women who were accompanied by young children (under 4 years of age) were approached, and only those who had breast-fed or were currently breast-feeding that infant were included, producing a convenience sample of 167 women. Although the 96 women surveyed in Córdoba were significantly more likely to have a college degree than were the 71 women in Buenos Aires, there were no significant differences in the demographic characteristics or the breast-feeding practices of the women from the two cities. Therefore, the two groups were combined for further analyses.

\section{Procedures}

A structured one-on-one interview was conducted to assess maternal beliefs and practices. Each woman was asked a series of questions about her infant's feeding practices and the types of advice, if any, the woman had received from health professionals (e.g., doctors, nurses) and from family members or friends or both (hereafter referred to as "family/friends") about alcohol usage during pregnancy, the peripartum period, and lactation (28). The mother was queried about whether she had treated her infant's umbilical cord stump with alcohol, and the length of time that the cord stump had taken to detach. Also included were questions related to the type of advice that the mother had received about mate. Each mother received a token gift (e.g., baby socks) for her participation in the study.

\section{Statistical analyses}

Cochran $\mathrm{Q}$ tests for related samples (36) were conducted to determine whether the type of advice women received about alcohol during pregnancy and lactation from health professionals differed from that from family/friends. The advice was categorized as "positive" (the woman was encouraged to drink alcohol), "negative" (she was advised to avoid drinking alcohol), or "no advice" (she received no advice). Because there is no determined "safe" amount of alcohol that can be consumed by women during pregnancy (5), any recommendation that encouraged alcohol consumption was recorded as "positive" (e.g., "drink less," "drink in moderation," or "drink beer to improve milk supply"). Similar analyses were also conducted to determine whether the type of advice women received about alcohol differed during pregnancy and lactation and to determine whether the type of advice women received from health professionals about the use of mate during lactation or the benefits of breast-feeding in general differed from that from family/friends. Additionally, $t$ tests for independent samples were used to determine whether soaking the cord stump with alcohol accelerated cord detachment when compared to not soaking the cord stump. All summary statistics are expressed as mean \pm standard error of the mean, and the critical value for significance was $P<0.05$.

\section{RESULTS}

\section{Subject characteristics}

Table 1 lists the characteristics of the 167 women in the sample. (The denominator for all the percentages presented below is 167, unless indicated otherwise.) The women were, on average, $27.9( \pm 0.5)$ years of age, and their infants (86 girls and 81 boys) were, on average, $9.4( \pm 0.6)$ months of age. Every woman reported that she met with her doctor during both pregnancy and the postpartum period. The vast majority of women (95.2\%) reported that their babies were being breast-fed at the time of hospital discharge. Of the 125 women who had a baby who was 4 months of age or older, 96 of them $(76.8 \%)$ reported that they breast-fed their baby to at least 4 months of age. Of the 84 women who had an infant older than 6 months, 58 of them $(69.0 \%)$ had breast-fed the child until at least 6 months of age.

\section{Advice regarding the consumption of alcoholic beverages during pregnancy}

As shown in Table 2, only $32.9 \%$ of the women were advised by their doctors to avoid or abstain completely from alcohol during pregnancy. The remaining mothers were either advised to drink in moderation $(13.8 \%)$ or received no advice regarding alcohol consumption from a health professional $(53.3 \%)$. A similar pattern emerged when we analyzed the type of advice received from family/friends (Table 3).

\section{Treating an infant's umbilical cord stump with alcohol}

The vast majority $(93.4 \%)$ of the women reported that they had treated 
TABLE 1. Characteristics of the 167 women in study of breast-feeding and alcohol, Argentina, 2001-2002

\begin{tabular}{|c|c|c|}
\hline Characteristic & No. & $\begin{array}{l}\text { Percentage } \\
\text { of sample }\end{array}$ \\
\hline \multicolumn{3}{|l|}{ Age of mother (yr) } \\
\hline$<20$ & 7 & 4.2 \\
\hline 20 to 24 & 34 & 20.4 \\
\hline 25 to 29 & 66 & 39.5 \\
\hline 30 to 34 & 37 & 22.1 \\
\hline 35 or older & 23 & 13.8 \\
\hline \multicolumn{3}{|l|}{ Marital status } \\
\hline Married & 99 & 59.3 \\
\hline Divorced & 3 & 1.8 \\
\hline Separated & 4 & 2.4 \\
\hline Single, living w/child's father & 34 & 20.3 \\
\hline Single & 27 & 16.2 \\
\hline \multicolumn{3}{|l|}{ Mother's education (completed) } \\
\hline No school & 2 & 1.2 \\
\hline Grade school & 57 & 34.1 \\
\hline High school & 59 & 35.3 \\
\hline College & 49 & 29.4 \\
\hline \multicolumn{3}{|l|}{ Mother works outside the home } \\
\hline Yes & 60 & 35.9 \\
\hline No & 98 & 58.7 \\
\hline Missing information & 9 & 5.4 \\
\hline \multicolumn{3}{|l|}{ Birth type } \\
\hline Natural delivery & 107 & 64.1 \\
\hline Cesarean & 60 & 35.9 \\
\hline \multicolumn{3}{|l|}{ Parity of the mother } \\
\hline Primiparous & 84 & 50.3 \\
\hline Multiparous & 83 & 49.7 \\
\hline \multicolumn{3}{|l|}{ Sex of child } \\
\hline Female & 86 & 51.5 \\
\hline Male & 81 & 48.5 \\
\hline \multicolumn{3}{|l|}{ Age of child } \\
\hline$<4 \mathrm{mo}$ & 42 & 25.1 \\
\hline$>4 \mathrm{mo}$ to $6 \mathrm{mo}$ & 41 & 24.6 \\
\hline$>6 \mathrm{mo}$ to $12 \mathrm{mo}$ & 41 & 24.6 \\
\hline$>12 \mathrm{mo}$ to $42 \mathrm{mo}$ & 43 & 25.7 \\
\hline \multicolumn{3}{|l|}{ Currently Breastfeeding } \\
\hline Infant is $<4 \mathrm{mo}$ & 36 & 85.7 \\
\hline Infant is 4 to 6 months & 31 & 75.6 \\
\hline Infant is $>6$ to 12 months & 25 & 61.0 \\
\hline Infant is $>12$ to 42 months & 12 & 27.9 \\
\hline
\end{tabular}

their infant's umbilical cord stump with alcohol. Of these 156 women, 114 of them $(73.1 \%)$ briefly applied the alcohol to the cord each time they changed the baby's diapers, whereas the other $42(26.9 \%)$ soaked the cord with bandages containing the alcohol. The bandages were secured with binding and were replaced during the next diaper change.

Lore indicates that such treatment of the cord stump will facilitate detach- ment (23). However, with the infants in our study there was no significant difference in the amount of time for cord stump detachment for those infants whose cord stump was soaked with alcohol $(10.8 \pm 1.2$ days $)$ when compared to the infants whose cord stump was not soaked with alcohol (9.2 \pm 0.7 days; $t$ test (degrees of free$\operatorname{dom}(\mathrm{df})=140)=-1.14 ; P>0.25)$. In addition, 23 of the 167 mothers reported that they were advised that warm alcohol-soaked cloths applied to the infant's abdomen would alleviate stomachaches in the child. Ten of these 23 women reported using alcohol cloths for this purpose.

\section{Advice regarding consumption of alcoholic beverages during lactation}

As shown in Table 2, regardless of the type of advice received, the percentage of women whose health professionals talked to them about consuming alcoholic beverages significantly decreased from pregnancy $(46.7 \%)$ to lactation $(25.7 \%)$ (Cochran Q test $(\mathrm{df}=1)=22.23 ; P<0.001)$. In contrast, the mothers reported that they continued to receive counseling from family/friends about drinking alcohol during lactation (Table 3). In fact, there was no significant difference in the percentage of women receiving advice from family/friends during pregnancy vs. during lactation (Cochran $\mathrm{Q}$ test $(\mathrm{df}=1)=1.37, P=0.24)$. However, the type of advice differed as a function of the reproductive state of the mother. That is, family/ friends were significantly more likely to encourage drinking alcohol when women were lactating compared to when the women were pregnant (Cochran $\mathrm{Q}$ test $(\mathrm{df}=1)$ $=21.43, P<0.001)$. Moreover, $25.1 \%$ of the women were told by family/ friends that beer was a galactagogue, thus encouraging beer consumption during lactation.

\section{Advice regarding breast-feeding in general and mate}

Although a very large majority of mothers reported that both their physicians $(96.4 \%)$ and their family/ friends $(88.0 \%)$ recommended breastfeeding, the difference between the two groups was statistically significant $($ Cochran $\mathrm{Q}$ test $(\mathrm{df}=1)=8.91 ; P<$ 0.005). Physicians also made recommendations to $61.1 \%$ of the mothers regarding the scheduling of feeding, supplementation with a bottle, nursing techniques, and the mother's diet while lactating. Just under two-thirds 
TABLE 2. Percentage of women who reported receiving positive, negative, or no advice from health professionals concerning drinking alcoholic beverages during pregnancy and during lactation, Argentina, 2001-2002

\begin{tabular}{lcccc}
\hline \multirow{2}{*}{$\begin{array}{c}\text { Type of advice } \\
\text { received during lactation }\end{array}$} & \multicolumn{2}{c}{ Type of advice received during pregnancy } & & Total \% during \\
\cline { 2 - 3 } & Positive & Negative & None & lactation \\
\hline Positive & 3.0 & 1.2 & 2.4 & 6.6 \\
Negative & 2.4 & 13.7 & 3.0 & 19.1 \\
No advice & 8.4 & 18.0 & 47.9 & 74.3 \\
$\quad$ Total \% during pregnancy & 13.8 & 32.9 & 53.3 & 100.0 \\
\hline
\end{tabular}

TABLE 3. Percentage of women who reported receiving positive, negative, or no advice from family members and friends concerning drinking alcoholic beverages during pregnancy and during lactation, Argentina, 2001-2002

\begin{tabular}{lccrr}
\hline \multirow{2}{*}{$\begin{array}{c}\text { Type of advice } \\
\text { received during lactation }\end{array}$} & \multicolumn{2}{c}{ Type of advice received during pregnancy } & Total \% during \\
\cline { 2 - 3 } & Positive & Negative & None & \begin{tabular}{c} 
lactation \\
\hline Positive
\end{tabular} $5^{2.4}$ \\
Negative & 1.2 & 6.6 & 14.9 & 26.9 \\
No advice & 2.4 & 14.4 & 5.4 & 21.0 \\
$\quad$ Total \% during pregnancy & 9.0 & 33.6 & 37.1 & 52.1 \\
\hline
\end{tabular}

of the women $(64.7 \%)$ reported that health professionals and family/ friends encouraged them to drink certain beverages or eat certain foods as an aid to lactation. Interestingly, $44.3 \%$ of the mothers reported that they were advised to drink mate to increase their milk production. Family/friends were significantly more likely to give this advice than were physicians $(38.3 \%$ vs. $6.0 \%$, Cochran Q test $(\mathrm{df}=1)=44.18$; $P<0.001$ ). Moreover, women not only received the advice, $37.1 \%$ of them believed that mate enhanced lactational performance. The mothers who were interviewed reported that if they knew another woman was having problems producing milk, they would "certainly recommend mate to her."

\section{DISCUSSION}

In Argentina, as in other cultures, beliefs exist about the medicinal properties of alcohol during the peripartum and lactational periods. For example, the large majority $(93.4 \%)$ of the mothers whom we surveyed reported that they had used alcohol to clean the umbilical cord stump. Moreover, $26.9 \%$ of the mothers who used alcohol to treat the cord stump still practiced the ageold tradition of soaking the cord stump with bandages containing ethyl alcohol, with the belief that such practices protected the cord from infection and facilitated its detachment. However, such treatment of the cord did not facilitate detachment among the infants in our study, a finding that is consistent with recent clinical trials (23). Although smaller in number, some of the women also reported that they applied warm cloths soaked in alcohol to the infant's stomach area to alleviate a stomachache.

Approximately half of the women in our survey reported that they had received medical advice about drinking alcoholic beverages during pregnancy. However, only a quarter of the women received such advice during lactation. This low rate of health professionals advising women about alcohol consumption during lactation was not due to a lack of interaction between the physician and the woman since each woman in the study reported visiting the doctor at least once during the pregnancy and once during the postpartum period. All but 6 of the 167 women reported that during such visits their doctors encouraged them to breast-feed their babies.

Much more so than physicians, family/friends continued to give advice about alcohol during lactation. One-quarter of the women reported that they were encouraged by family/ friends to drink beer to promote milk production. Clinical research has shown that women who received advice from a physician to abstain from alcohol reported a lower risk of drinking during pregnancy (37). Future studies should investigate whether the type of advice (or lack thereof) that women receive influences their alcoholdrinking behaviors during both pregnancy and lactation (38).

Of the women whom we studied, $44.3 \%$ of them said that they were told, principally by family/friends, that drinking mate leads to increased milk production. There is no scientific evidence to support this popular belief, and it should be noted that mate contains caffeine and other methylxanthines. It has been reported that a typical mate drinker would ingest about 100-200 mg of caffeine a day, although some consume nearly $1 \mathrm{~g}$ a day (34). Caffeine may accumulate in the infant $(39,40)$, so if the mother consumes an excessive amount of the substance, that may cause wakefulness and hyperactivity in the baby (41). Thus, clinicians may want to inquire about this practice when discussing with the mother her dietary habits during pregnancy and lactation.

One reason why the lore that drinking alcohol benefits lactating women persists may be the striking paucity of research in this area. Both health professionals and the public at large lack important information on this crucial topic, and this may be one of the reasons that few health professionals provide counseling about alcohol. Despite 
two decades of consistent warnings that pregnant women should abstain from drinking alcohol, the vast majority of widely used medical textbooks fail to communicate this message unequivocally (42). A recent review of 81 obstetrical textbooks found that only $17 \%$ consistently recommended that pregnant women avoid drinking alcohol (42).

In Argentina and other nontemperance cultures, alcohol is integrated into daily food habits, religious rites, and social customs (22). This in turn may contribute to the underestimation of alcohol-related health problems in the population in general. To our knowledge there has been no research that has assessed women's alcohol consumption patterns during pregnancy and lactation. Nor do we know about the prevalence of alcoholism, alcohol abuse, and fetal alcohol syndrome among Argentines, or the quantity and frequency of drinking among people in the country. Although this specific information is lacking, the magnitude of the problem is indicated by the finding that liver cirrhosis ranked as one of the principal causes of deaths in Argentina during the 1980s (43). Moreover, a recent report by the Pan American Health Organization indicated that alcoholism remains one of the top pathologies in Argentina, with its greatest impact being among the youth in the country (44).

Our research found that the majority of the women whom we surveyed had not been counseled by their health professionals on alcohol usage during pregnancy and lactation. Therefore, there is a need to develop culturally appropriate professional development strategies to increase both health professionals' and patients' awareness of the risks of alcohol consumption during pregnancy and lactation, and to provide accurate information to both of those groups on the risks of alcohol exposure to the fetus and neonate. In order to understand why women drink during pregnancy and lactation or expose a newborn to high levels of alcohol when treating the infant's umbilical cord stump, we believe that the historical dimension of these individual and group practices must be explored. Research now going in Argentina (18-20) and in the United States $(14,21,45,46)$ aims to determine how beliefs about alcohol's efficacy and its hazards affect the behavior of the mother and, in turn, an infant's responsiveness to alcoholic beverages as a result of early sensory experiences.

Acknowledgments. This work was supported by Grant AA09523 from the National Institute on Alcohol Abuse and Alcoholism of the United States. We would like to acknowledge Dr. Paula Abate and Ms. Alejandrina López Peña for their excellent technical support and Drs. Juan Carlos Molina and Catherine Forestell for their comments on an earlier version of this manuscript.

\section{REFERENCES}

1. Eustace LW, Kang DH, Coombs D. Fetal alcohol syndrome: a growing concern for health care professionals. J Obstet Gynecol Neonatal Nurs. 2003;32(2):215-21.

2. Warren KR, Foudin LL. Alcohol-related birth defects-the past, present, and future. Alcohol Res Health. 2001;25(3):153-8.

3. Riley EP, Mattson SN, Li TK, Jacobson SW, Coles CD, Kodituwakku PW, et al. Neurobehavioral consequences of prenatal alcohol exposure: an international perspective. Alcohol Clin Exp Res. 2003;27(2):362-73.

4. International Center for Alcohol Policies. Government policies on alcohol and pregnancy (December 1999) [Internet site]. Available from: http://www.icap.org/pdf/report6. pdf. Accessed 5 September 2004.

5. American Academy of Pediatrics Committee on Substance Abuse and Committee on Children with Disabilities. Fetal alcohol syndrome and fetal alcohol effects. Pediatrics. 1993;91(5): 1004-6.

6. Kesaniemi YA. Ethanol and acetaldehyde in the milk and peripheral blood of lactating women after ethanol administration. J Obstet Gynaecol Br Commonw. 1974;81(1):84-6.

7. Lawton ME. Alcohol in breast milk. Aust N Z J Obstet Gynaecol. 1985;25(1):71-3.

8. Mennella JA, Beauchamp GK. The transfer of alcohol to human milk. Effects on flavor and the infant's behavior. N Engl J Med. 1991;325 (14):981-5.

9. Mennella JA, Beauchamp GK. Effects of beer on breast-fed infants. JAMA. 1993; 269(13): 1637-8.

10. American Academy of Pediatrics. The transfer of drugs and other chemicals into human milk. Pediatrics. 2001;108(3):776-89.

11. Mennella JA, Gerrish CJ. Effects of exposure to alcohol in mother's milk on infant sleep. Pediatrics. 1998;101(5):E2.

12. Mennella JA, Garcia-Gomez PL. Sleep disturbances after acute exposure to alcohol in mothers' milk. Alcohol. 2001;25(3):153-8.

13. Mennella JA. Regulation of milk intake after exposure to alcohol in mothers' milk. Alcohol Clin Exp Res 2001;25(4):590-3.

14. Mennella JA. Infants' suckling responses to the flavor of alcohol in mothers' milk. Alcohol Clin Exp Res. 1997;21(4):581-5.

15. Mennella JA. Short-term effects of maternal alcohol consumption on lactational performance. Alcohol Clin Exp Res. 1998;22(7): 1389-92.

16. Little RE, Anderson KW, Ervin $\mathrm{CH}_{4}$ Worthington-Roberts B, Clarren SK. Maternal alcohol use during breast-feeding and infant mental and motor development at one year. N Engl J Med. 1989;321(7):425-30.

17. Domínguez HD, López MF, Molina JC. Neonatal responsiveness to alcohol odor and infant alcohol intake as a function of alcohol experience during late gestation. Alcohol. 1998; 16(2):109-17.

18. Molina JC, Domínguez DH, López MF, Pepino MY, Faas AE. The role of fetal and infantile experience with alcohol in later recognition and acceptance patterns of the drug. In: Hannigan JH, Spear N, Spear L, Goodlett CR, eds. Alcohol and alcoholism: brain and development. Hillsdale: Lawrence Erlbaum Associates; 1999. Pp. 199-228.

19. Pepino MY, Abate P, Spear NE, Molina JC. Heightened ethanol intake in infant and adolescent rats after nursing experiences with an ethanol-intoxicated dam. Alcohol Clin Exp Res. 2004;28(6):895-905.

20. Faas AE, Sponton ED, Moya PR, Molina JC. Differential responsiveness to alcohol odor in human neonates: effects of maternal consumption during gestation. Alcohol. 2000;22 (1):7-17.

21. Mennella JA, Beauchamp GK. Infants' exploration of scented toys: effects of prior experiences. Chem Senses. 1998;23(1):11-7.

22. Peele S. Utilizing culture and behavior in epidemiological models of alcohol consumption and consequences for Western nations. Alcohol Alcoholism. 1997;32(1):51-64.

23. Dore S, Buchan D, Coulas S, Hamber L, Stewart M, Cowan D, et al. Alcohol versus natural drying for newborn cord care. J Obstet Gynecol Neonatal Nurs. 1998;27(6):621-7. 
24. Golombek SG, Brill PE, Salice AL. Randomized trial of alcohol versus triple dye for umbilical cord care. Clin Pediatr (Phila). 2002;41 (6):419-23.

25. Janssen PA, Selwood BL, Dobson SR, Peacock D, Thiessen PN. To dye or not to dye: a randomized, clinical trial of a triple dye/alcohol regime versus dry cord care. Pediatrics. 2003; 111(1):15-20.

26. Choonara I. Percutaneous drug absorption and administration. Arch Dis Child. 1994;71: F73-F74.

27. Dalt LD, Dall'Amico R, Laverda AM, Chemollo C, Chiandetti L. Percutaneous ethyl alcohol intoxication in a one-month-old infant. Pediatr Emerg Care. 1991;7(6):343-44.

28. Mennella JA. The transfer of alcohol to human milk: sensory implications and effects on mother-infant interaction. In: Hannigan $\mathrm{JH}$, Spear N, Spear L, Goodlett CR, eds. Alcohol and alcoholism: brain and development. Hillsdale: Lawrence Erlbaum Associates; 1999. Pp. 177-98.

29. Mennella JA. Alcohol use during lactation: the folklore versus the science. In: Auerbach $\mathrm{KG}$, ed. Current issues in clinical lactation. Boston: Jones and Bartlett Publishers; 2002. Pp. 3-10.

30. Flores-Huerta S, Hernández-Montes H, Argote RM, Villalpando S. Effects of ethanol consumption during pregnancy and lactation on the outcome and postnatal growth of the offspring. Ann Nutr Metab. 1992;36(3):121-8.
31. Fishman C, Evans R, Jenks E. Warm bodies, cool milk: conflicts in post partum food choice for Indochinese women in California. Soc Sci Med. 1988;26(11):1125-32.

32. Revista de Vinos. La degustación de la cerveza [Internet site]. Available from: http://clubdevino.com/cerveza /LaCerveza Degustacion.html\#Salud. Accessed 5 September 2004.

33. Walter M. The folklore of breastfeeding. Bull N Y Acad Med. 1975;870-6.

34. Vázquez A, Moyna P. Studies on mate drinking. J Ethnopharmacol. 1986;18(3):267-72.

35. Hoss de le Comte M. The mate. Buenos Aires: Maizal; 1999.

36. Siegel S, Castellan NJ. The case of $\mathrm{k}$ related samples. In: Anker JD, ed. Nonparametric statistics for behavioral sciences. New York: McGraw-Hill; 1988. Pp. 170-4.

37. Jones-Webb R, McKiver M, Pirie P, Miner K. Relationships between physician advice and tobacco and alcohol use during pregnancy. Am J Prev Med. 1999;16(3):244-7.

38. Blume SB. Iatrogenic alcoholism. Q J Stud Alcohol. 1973;34(4):1348-52.

39. Cazeneuve C, Pons G, Rey E, Treluyer JM, Cresteil T, Thiroux G, et al. Biotransformation of caffeine in human liver microsomes from fetuses, neonates, infants and adults. Br J Clin Pharmacol. 1994;37(5):405-12.

40. Le Guennec JC, Billon B. Delay in caffeine elimination in breast-fed infants. Pediatrics. 1987;79(2):264-8.
41. Lawrence RA. Drugs in breast milk. In Breastfeeding: a guide for the medical profession. St. Louis: C.V. Mosby Company; 1989

42. Loop KQ, Nettleman MD. Obstetrical textbooks: recommendations about drinking during pregnancy. Am J Prev Med. 2002;23(2): 136-8.

43. Hauger-Klevene JH, Balossi EC. Liver cirrhosis mortality in Argentina: its relationship to alcohol intake. Drug Alcohol Depend. 1987;19 (1):29-33.

44. Pan American Health Organization. Profile of the health services system Argentina. 2nd ed. Available from: http://www.lachsr.org/ documents/healthsystemprofileofargentinaEN.pdf. Accessed 5 September 2004.

45. Mennella JA. Alcohol use during lactation: effects on the mother and breastfeeding infant. In: Watson R, ed. Nutrition and alcohol. Second edition. Boca Raton: CRC Press; 2004. Pp. 377-91.

46. Petrov ES, Varlinskaya EI, Spear NE. Reinforcement from pharmacological effects of ethanol in newborn rats. Alcohol Clin Exp Res. 2003;27(10):1583-91.

Manuscript received 4 March 2004. Revised version accepted for publication 8 September 2004.
RESUMEN

\section{Consejos dados a las mujeres en Argentina acerca de la lactancia materna y el consumo de alcohol}

Objetivo. Explorar el tipo de consejos que los profesionales de la salud, parientes y amigos le dieron a una muestra de mujeres en Argentina acerca del consumo de bebidas alcohólicas y el uso de alcohol durante el embarazo y la lactancia.

Métodos. En diciembre de 2001 y diciembre de 2002 se llevaron a cabo entrevistas estructuradas con un total de 167 mujeres que estaban amamantando o que habían amamantado recientemente. A las madres se les preguntó qué tipo de consejos, en caso de haberlos, les dieron los profesionales de la salud y sus parientes y amistades acerca del consumo de alcohol. También se plantearon preguntas sobre la bebida tradicional argentina, el mate -infusión muy popular en América del Sur que se prepara con las hojas de la planta Ilex paraguayensis - y la clase de consejos que recibieron las mujeres acerca de la lactancia materna y los cuidados neonatales en general.

Resultados. De las 167 mujeres estudiadas, 96,4\% indicaron que el médico les había aconsejado que amamantaran a su hijo. Además, 93,4\% afirmaron que habían frotado con alcohol el muñón umbilical del niño. Menos de la mitad de las mujeres $(46,7 \%)$ indicaron haber recibido del médico asesoramiento acerca del consumo de bebidas alcohólicas durante el embarazo, y un porcentaje aun menor $(25,7 \%)$ indicó haber recibido este tipo de asesoramiento durante la lactancia. Los parientes y amigos mostraron aproximadamente la misma propensión a aconsejar acerca del consumo de bebidas alcohólicas durante el embarazo $(42,6 \%)$ y la lactancia $(47,9 \%)$. No obstante, el tipo de consejo fue distinto en uno y otro caso, en el sentido de que los parientes y amigos mostraron una proclividad mayor (en grado estadísticamente significativo) a alentar a la mujer a consumir bebidas alcohólicas durante la lactancia que durante el embarazo $(P<0,001)$. Los parientes y amigos también alentaron el consumo de mate para estimular la producción de leche.

Conclusiones. Como en otros contextos culturales, en Argentina existe la creencia de que el alcohol mejora la lactancia. Sin embargo, la mayoría de las mujeres entrevistadas no habían recibido asesoramiento profesional acerca del consumo de bebidas alcohólicas durante el embarazo y la lactancia. Se necesitan estrategias profesionales orientadas a lograr que las mujeres cobren mayor conciencia de los riesgos asociados con el consumo y uso del alcohol. 